\title{
Da governabilidade do mytos ao esclarecimento do logos: Narciso, Odisseu e os padrões de beleza corporal
}

\author{
Renato Izidoro da Silva* \\ Fabio Zoboli*
}

\begin{abstract}
Resumo: Este trabalho é a síntese de uma pesquisa filosófica mais ampla que apresenta os fundamentos epistemológicos de mythos e logos e as suas relações com a experiência Ocidental. O texto tenciona os conflitos e contradições da relação mythos e logos no que tange os problemas da governabilidade e o esclarecimento dos indivíduos, tendo como ancoragem os comportamentos e padrões de beleza corporal na modernidade. Para tanto, suspendemos os mitos de Odisseu e Narciso para, em face ao homem moderno alienado ao mito do corpo belo, defender a tese de que a condição mito-lógica do homem é insuperável.
\end{abstract}

Palavras chave: Mythos/Logos. Padrões de beleza corporal. Governabilidade. Esclarecimento.

\section{INTRODUÇÃO}

Como é possível interpretar a relação do corpo com os padrões de beleza na contemporaneidade por meio do mito, de modo que a mitologia nos revela algo mais do que apenas o logos? Como o logos se apropria do corpo para dominar sua natureza e torná-lo belo? Como o logos precisa do mito para convencer os indivíduos a serem belos? Onde está o trágico do mito em relação ao logos na busca pela beleza corporal na modernidade?

Este texto compreende um estudo sobre a relação entre mito e $\log$ os e seus reflexos na modernidade, mais especificamente

\footnotetext{
'Professor do Departamento de Educação Física, Universidade Federal de Sergipe, Aracajú, SE. E-mail: izidoro.renato@gmail.com

"Professor do Departamento de Educação Física, Universidade Federal de Sergipe, Aracajú, SE. E-mail: zobolito@gmail.com
} 
enquanto uma possível lente interpretativa às voltas da constituição dos padrões de beleza corporal como problema da governabilidade. O mito e o logos dizem respeito, distintamente, a regimes de símbolos abstratos e concretos capazes de fundar e reger a sensibilidade, o pensamento e o comportamento social, cultural, político e econômico de uma dada sociedade e de seus indivíduos em relação uns aos outro e a si próprios.

No contexto das produções acadêmico-científicas periódicas da Educação Física, temáticas relacionadas ao mito e aos padrões de beleza corporal são frequentemente abordadas tanto separadamente quanto correlacionadas. Sobre mito, as publicações foram desenvolvidas em termos analógicos, alegóricos e metafóricos no sentido de desvendar ou sugerir significações subentendidas ou novas acerca de temáticas específicas da área; supondo semelhança com os mitos gregos especialmente. Todavia, foi possível notar que os autores partem de alguma narrativa mítica em particular, sem recorrer aos estudiosos da mitologia, caracterizando os trabalhos alegóricos de um ponto de vista ensaístico, sugestivo e intuitivo. Isso quando a palavra mito não aparece nos textos de modo aleatório e sem qualquer rigor - maioria dos trabalhos - apenas para designar noção de engano, ilusão, alienação, idolatria, ideologia, imaginário etc.. ${ }^{1}$ Já no âmbito das pesquisas que versam sobre o corpo e a beleza no campo da Educação Física foram encontrados inúmeros textos nos periódicos veiculados a área que versam sobre esta temática a partir de diversos olhares temáticos ${ }^{2}$.

\footnotetext{
${ }^{1}$ Essas considerações foram formuladas com base em um levantamento introdutório realizado no âmbito de seis periódicos da Educação Física os quais demonstram a seguinte configuração: utilizando a ferramenta de busca online das revistas, selecionando do critério/filtro "todos", foram identificados, associados à palavra "mito", as seguintes quantidades de publicações: a) RBCE: 00; b) Movimento: 74; c) Motrivivência: 01; d) Pensar a Prática: 21; e) Motriz: 33; f) Revista de Educação Física da UEM: 01.

${ }^{2} \mathrm{~A}$ partir de uma pesquisa bibliométrica realizado no âmbito de seis periódicos da Educação Física identificamos que o escopo sobre a temática é imenso, por tal motivo foi necessário centrar nossa procura utilizando a ferramenta de busca online das revistas, selecionando o critério/filtro limitado a "resumos" e "títulos" os quais nos levaram a alguns artigos sobre a temática do corpo e da beleza, desta forma visualizamos: a) RBCE: 06; b) Movimento: 07; c) Motrivivência: 04; d) Pensar a Prática: 06; e) Motriz: 11; f) Revista de Educação Física da UEM: 01.
} 
A partir de uma pesquisa em periódicos de Educação Física visualizamos alguns trabalhos que se alinhavam com nosso estudo na medida em que utilizam o mito como pano de fundo para discorrer uma determinada temática: Silva e Gomes (2008) analisam os resultados obtidos em seu estudo a partir de uma correlação por semelhança entre os corpos ensolarados e o mito de Apolo, a civilização dos corpos malhados e o país dos hiperbóreos. O estudo de Rinaldi, Lara e Rinaldi (2008) a partir de uma pesquisa refletem o entendimento de atividade física e saúde a partir do discurso do sujeito coletivo, identificando e analisando as categorias originárias à luz do mito de Ulisses e as sereias, presente na obra clássica Odisséia, de Homero. Outro estudo semelhante a este último, porém veiculado num periódico de Saúde Pública, é o de Melo-Filho (1995) que analisa a saúde, o indivíduo e a história estabelecendo uma metáfora com o personagem mitológico Ulisses de Homero e o personagem Fausto, de Goethe.

O presente escrito parte da hipótese de que a busca pelo corpo belo é pautada pelo mito da beleza criado e propagado pelo logos que cria tecnologias que alimentam o mercado do corpo. Essa trama se dá a partir de um sistema de engrenagens que faz girar toda uma política que dá sentido e sustentação a elas. O trágico, na busca pelo corpo belo mediante o logos, dá-se na medida em que o sujeito permanece amarrado à sua condição de natureza, bem como às demandas sociais concernentes ao belo.

O trágico do corpo belo enquanto natureza é a sua inexorável degradação pelo tempo, apesar das técnicas e tecnologias - neste sentido o sujeito fica preso a Chronus (o deus do tempo), pois a idade irá fragilizar o mesmo até que Thanatos (o deus da morte) "vier lhe beijar a boca". A tragédia na dimensão da demanda social faz com que o sujeito encarne o drama de $\mathrm{Sísifo}^{3}$, num eterno trabalho diário na busca pelo belo.

\footnotetext{
${ }^{3}$ Existem três versões para o mito de Sísifo, mas todas elas desencadeiam um mesmo fim trágico: o castigo proferido a Sísifo pelos deuses. Por toda a eternidade, Sísifo foi condenado a rolar uma grande pedra com suas mãos até o cume de uma montanha, sendo que toda vez que ele está alcançando o topo, a pedra rola novamente montanha abaixo, até o ponto de partida.
} 
Aquele que está sujeito ao destino, tanto no pensamento mitológico quanto no pensamento filosófico, luta de modo inútil contra sua destinação; com a diferença que o pensamento mitológico, fundado em seu caráter trágico, implica uma comprovação e revelação da sujeição do ser ao destino; enquanto que o filósofo ou a filosofia, por não ser algo da ordem do divino, mas sim da vida humana, sempre guarda a esperança de poder se libertar de seu destino por meio da clarividência do logos, que para os modernos é chamado de esclarecimento diante da alienação e obscuridade do mito.

Em termos historiográficos, tornou-se lugar comum relacionar mito e logos não apenas nas suas disputas, mas também na ruptura que o segundo realiza em relação ao primeiro, principalmente na emergência do logos no exercício do pensamento filosófico que implica uma ruptura com o mito no sentido de sua superação e consequente substituição moderna, paradigmática ou epistêmica (VERNANT, 2006).

De acordo com a compreensão antropológica de Jesi (1988, p. 77) acerca da operação mitológica na vida terrena dos homens, "[...] a mitologia não explica nada, mas <<espalha claridade sobre o que é, acontece e deve acontecer $>>$ ". Está nítido o teor determinista do mito relativo ao sentido do destino dos homens, individual e socialmente tratado. $\mathrm{O}$ mito tem a função de revelar ao cidadão sua condição irreversível no interior de uma situação que o supera e o transcende em termos de poder sobre seu destino. A condição terrena do homem é governada por fatores maiores que sua consciência, que seu pensamento é capaz de antecipar.

É nesse sentido que a "mito-lógica" deve estar ligada à lei do eterno retorno do mesmo, como o aprisionamento do homem a uma temporalidade e a uma materialidade históricas insuperáveis e incontornáveis. O domínio histórico do mito se revela como o oposto da história moderna instalada pela dialética hegeliana e marxiana, que implica a superação da repetição da história mitológica para a fundação de um novo destino para os homens. Tomando como exemplo a trilogia mitológica de Édipo, podemos observar a função 
de afirmação e aprisionamento do homem em sua condição terrena em oposição à onipresença e onividência dos deuses. $\mathrm{O}$ mito de Édipo é a consciência dos deuses mostrando e fazendo o homem provar a condição limitada de seu poder. O homem, como um coitado, fadado ao engano e ao erro, mata o pai e se casa com a própria mãe sem saber. O esclarecimento advém não da superação e da antecipação ao erro, mas sim após sua confirmação ou constatação; momento em que o mito mostra ao homem sua condição histórica incontornável, inevitável e trágica.

A história moderna, assim como Odisseu, pretende ser o oposto, mostrando que o logos pode superar o mito, como fez Odisseu, que, pelo logos, derrotou os deuses transcendendo sua condição trágica/ mitológica. Não é à toa que Adorno e Horkheimer (1985, p. 63) compreendem a epopeia homérica de Odisseu como uma alegoria da autoafirmação da civilização. Assim, o estudo do mito na modernidade pode se justificar na medida em que Vernant (2006, p. 200) explicita que o "[...] 'absurdo' [do mito] não é mais denunciado como um escândalo lógico; é sentido como um desafio lançado à inteligência científica a quem se deve o realce e a compreensão desse outro que é o mito, e sua incorporação ao saber antropológico".

Sendo assim este escrito foi dividido em duas partes: num primeiro momento do texto, apresentamos os fundamentos epistemológicos de mythos e logos e as suas relações com a experiência Ocidental. A partir desta exposição, abordaremos como os conflitos, tensões e contradições entre mythos e logos contracenam com o problema da governabilidade e o esclarecimento dos indivíduos, tendo como ícone o personagem Odisseu. Na segunda e última parte, o texto apresenta as relações entre mythos e logos, tendo como ancoragem os padrões de beleza corporal na modernidade. Aqui o corpo é suspendido para, a partir da constituição dos padrões de belo, estabelecermos tensões entre o mythos e o logos, defendendo a tese de que a modernidade sustenta o mito da beleza a partir da racionalidade - logos - mercadológica e de consumo. 


\section{Odisseu: tensões entre Mythos e Logos}

Para Jesi (1988, p. 15), o homem na Grécia Antiga e Arcaica, para ser um grande homem, deveria ser a mistura dos contrários: mythos e logos.

A união destas duas capacidades no mesmo homem
era o fim da educação ministrada por Fénix a Aquiles
(Ilíada, IX, 440 seg.), para que o jovem herói fosse
ao mesmo tempo <<eloquente〉> (mythón te rhéter)
e <<realizador de obras〉> (préktérá te érgón). O
homem completo devia saber unir à acção [sic],
simbolizada pela destreza no uso de armas, o talento
de agir com palavras [...], talento em que brilhou
Ulisses, o herói <<dos múltiplos modos do
discurso>> (polytropos), que também foi valente
guerreiro.

Segundo Vernant (2006), a palavra mythos designa uma narrativa, um diálogo ou enunciação de um projeto. Embora Vernant não ofereça detalhes sobre o motivo de ter aplicado a palavra "projeto" de uma perspectiva historiográfica e antropológica presente, a relação entre mythos e projeto - do lat. projectus - deve estar vinculada à noção de destino: do lat. destinare, que significa fixar e determinar com antecipação. Para Japiassú e Marcondes (2001), o destino é tradicionalmente interpretado como uma instância universal governante de todos os movimentos de modo irremediável ou incontornável. O destino, portanto, pode ser visto como uma força transcendente às condições objetivas terrenas capazes de configurar um poder limitado dos seres humanos concernente ao governo acerca de como nascem, vivem e morrem.

Confunde-se destinação com fatalismo, pois, como veremos na sequência, o destino, embora determinista, implica uma luta de seu sujeito contra ele - diferente do fatalista, que se entrega ao destino sem lutar, como é o caso de Édipo, que perde para seu destino, tendo de ficar cego para poder iluminar o que não era capaz de ver, justamente por não ter sido capaz de decifrar por meio do logos a 
mitologia na qual ele mesmo estava inserido. Assim, ao mesmo tempo em que o mito é a constatação de sua alienação, essa mesma constatação significa a revelação ou iluminação da verdade, mas não por antecipação, como pretende a filosofia e a ciência, mas sim mediante o exercício de refletir sobre o que passou, acerca do que não tem mais volta.

$\mathrm{Na}$ medida em que o conceito filosófico de projeto significa o fato de o ser sempre estar lançado para além de si mesmo, conforme a acepção de Heidegger, segundo Japiassú e Marcondes (2001), é possível atrelar esse conceito ao que é designado como mythos na Grécia, enquanto uma narrativa responsável por revelar o destino incontornável da humanidade e de cada um de seus indivíduos, mesmo que por meio do logos o homem busque tomar as rédeas e o governo de seu destino, deslocando-se de um essencialismo a um existencialismo, para o qual o projeto do destino é passível de ser escolhido pelos homens a partir de suas condições materiais terrenas. O projeto visa libertar o homem do ciclo mítico e trágico da história.

As contradições entre mythos e logos na Grécia, de um ponto de vista histórico e antropológico, consiste em ser um dos principais fundamentos epistemológicos da fundação da experiência Ocidental no campo das batalhas entre religião e filosofia/ciência: relação de ruptura entre o Antigo e o Novo Regime a partir da guerra que o movimento Iluminista coloca em prática contra o pensamento Medieval vigente e regente na Europa até o século XVII, análogo ao que tentaram realizar Sócrates, Platão e Aristóteles contra o regime mítico da polis grega.

Essa aproximação entre Grécia Clássica e Modernidade não implica um anacronismo, porque a Modernidade nasce a partir de um movimento intelectual e político chamado Iluminismo ou Esclarecimento, cujas bases epistemológicas estão assentadas na retomada historiográfica do pensamento racionalista dos gregos clássicos, também conhecida como Renascimento; uma das armas para a filosofia medieval se apartar e atacar a hegemonia do 
pensamento abstrato e ritualístico da Igreja Católica e toda sua mitologia bíblica responsável por governar os corpos e os intelectos da época.

A relação entre mythos e logos nos remete a algum ponto de vista historiográfico e etnológico acerca do pensamento grego em seus períodos Antigo e Clássico. Politicamente, implica uma relação de disputa entre as mitologias antigas e a filosofia clássica dos gregos no que concerne ao governo a ser exercido a polis. É preciso compreender que a filosofia grega nasce como uma oposição ao pensamento mitológico. A morte de Sócrates, que cometeu o crime de se lançar criticamente contra os mitos, pode ser vista como um momento auge do conflito entre pensamento mítico e pensamento filosófico. A República, de Platão, é o projeto de uma sociedade governada pelo logos em ruptura com a sociedade mitológica, cujos divulgadores e escritores eram os poetas, sendo os nomes mais emblemáticos Homero e Hesíodo (VERNANT, 2006).

Conforme Vernant (1990, p. 19), a "[...] última razão [...] que orienta através da Antiguidade Clássica o historiador do homem interior [grego] [...] [é a constatação historiográfica acerca de um período em que] a Grécia conheceu, em sua vida social e espiritual, transformações decisivas". Trata-se de uma transformação marcada pelo nascimento da Cidade e do direito relacionado ao pensamento de tipo racional por parte dos primeiros filósofos, caracterizado por uma organização progressiva do saber mediante um corpo de disciplinas: matemática, ciência da natureza, medicina e política.

Nesse sentido, a República platônica significa um novo projeto para a humanidade grega, segundo outra destinação, agora governada pelo logos, assim como os movimentos republicanos na Europa também implicavam a defesa contra determinismos acerca da condição terrena e insuperável da humanidade, no século XVIII, propagados pela Igreja Católica e Monarquias como amparadas e governadas segundo os domínios vigentes do mito em sua forma religiosa (VERNANT, 2006). No caso de Odisseu, o sucesso de seu retorno para casa afirma a capacidade humana de enfrentar os 
deuses e a natureza, bem como a força em se manter a unidade política da família e da cidade pautadas na memória, na linguagem, na técnica, na tecnologia e na astúcia (GAGNEBIN, 2006).

Essa profunda mudança de mentalidade - do mito ao logos supostamente ocorrida na Grécia entre os séculos VIII e VI a.C. está associada ao nascimento do homem ocidental (VERNANT, 1990), a desembocar no homem moderno, um dos fios condutores de a "Dialética do esclarecimento", de Adorno e Horkheimer. Segundo Gagnebin (2006, p. 13), a "[...] leitura de Adorno e Horkheimer, representa [...] a formação do sujeito pela dominação da natureza e pela autorrepressão, paradigma da violência necessária para o estabelecimento da razão instrumental e da identidade subjetiva". Odisseu representa a saída da infância dos homens perante os deuses, ascendendo a uma idade adulta enquanto dominação racional expressa nas negociações pacientes com sua natureza interna, com a natureza do outro e dos fenômenos extra-humanos, mediante repressões e liberações sacrificiais objetivas e subjetivas, que implicam a reorganização política da Grécia em torno de Zeus e do patriarca.

Entretanto, aceitamos como significativo o fato de Adorno e Horkheimer tomarem Odisseu como a emergência da civilização moderna centrada na techné e no logos instrumental, em vez de impor essa influência ou culpa sobre Sócrates, como fez Nietzsche em seu "O nascimento da tragédia". Ambos os filósofos encontram em Odisseu o protótipo do homem moderno, justamente porque se trata de um homem que vive o mythos e o logos no plano dos conflitos e dos esclarecimentos possíveis entre ambos os contrários, em vez de pensar o homem do Iluminismo como aquele que superou sua condição mito-lógica em prol da lógica. $\mathrm{O}$ fundamento da civilização ocidental e moderna não seria a República platônica, pois, conforme Adorno e Horkheimer (1985, p. 49), "[...] nenhuma obra presta um testemunho mais eloquente do entrelaçamento do esclarecimento e do mito do que a obra homérica, o texto fundamental da civilização europeia". 
A Odisséia de Homero retrata a luta do homem - Odisseu contra os poderes divinos acerca do governo do logos pelo mythos. Gagnebin (2006) compreende que a Odisséia destaca não apenas a luta de Odisseu para retornar ao seu lar/família em Ítaca, pois, para isso ocorrer, o herói humano deve manter sua memória, as histórias, os cantos etc., diante das tentativas divinas de roubar-lhe tudo isso, ou seja, retirar-lhe seu domínio do logos. Em oposição ao anonimato dos poetas mitológicos, o protagonista da Odisseia assume a autoria da vitória dos gregos sobre os troianos, principalmente porque atribui a si a ideia de construir, de modo astuto, o Cavalo de Tróia, como uma arma de guerra para penetrar, não pela força, mas pela inteligência, os muros troianos.

Ao se assumir enquanto vitorioso Odisseu desdenha da influência dos deuses sobre as destinações humanas. Consequentemente, Poseidon, deus dos mares, fica furioso com Odisseu e promete fazer com que o mesmo se perca em sua viagem náutica e nunca mais retorne à sua cidade, Ítaca, onde o esperam sua esposa, Penélope, e seu filho, Telêmaco. Além desse episódio, Odisseu ofende mais uma vez Poseidon, quando, por uma astúcia, consegue enganar o filho do olimpiano, o ciclope Polifemo. Odisseu e seus companheiros, no caminho de volta para a casa, invadem a terra dos ciclopes e adentram a caverna de Polifemo. Após oferecerem vinho ao ciclope, fazendo com que dormisse; Odisseu arquiteta um plano para que ele e seus companheiros consigam vazar o único olho de Polifemo.

Por consistir em um plano, Odisseu pensou antes e revelou ao seu inimigo uma identidade falsa, denominada "ninguém", como sendo seu nome. Ao gritar após ter o olho vazado, Polifemo berra aos outros ciclopes que "ninguém" furara seu olho, sendo jogado no campo das ambiguidades da palavra e da linguagem, de modo a ser ignorado pelos outros ciclopes, permitindo a fuga de Odisseu rumo ao barco, que deveria seguir até Ítaca. Contudo, não contente com seu feito, à distância, Odisseu revela ao ciclope sua identidade, anunciando seu nome. Enfurecido, Polifemo arremessa uma rocha contra a embarcação. O ciclope pede a seu pai, Poseidon, que impeça o 
retorno de Odisseu até seu lar. Mais uma vez, o protagonista homérico assume uma autoria astuta pelo seu feito, o qual é interpretado pelos estudiosos como uma astúcia fruto do logos dos homens contra o mythos dos deuses.

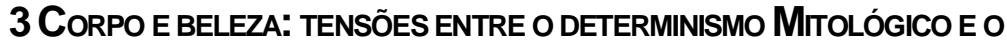 LOGOS MODERNO}

A partir de agora vamos desenvolver algumas questões decorrentes do exame da relação entre mythos e logos a partir da constituição do padrão de beleza corporal na modernidade. Para tal, nos utilizamos de substratos mitológicos com o intuito de, na figura de Narciso - representante do mito e da condição trágica da governabilidade -, estabelecermos as tensões com Odisseu representante do logos.

Quando Prometeu rouba o fogo de Zeus para dar aos homens, ele inaugura a técnica, o domínio da natureza. Agora não é mais Zeus o dono do conhecimento sobre o mundo. Quando Prometeu toma de Zeus o fogo, ele tira o homem de sua dependência da natureza, ele sai de sua condição trágica de ficar submisso às vontades dos deuses.

O fogo lhe forneceu o meio de construir as armas com que subjugou os animais e as ferramentas com que cultivou a terra; aquecer sua morada, de maneira a tornar-se relativamente independente do clima, e, finalmente, criar a arte da cunhagem das moedas, que ampliou e facilitou o comércio (BULFINCH, 2002, p. 20).

A nosso ver, Adorno e Horkheimer apreendem Odisseu como um Prometeu humano. De acordo com Gagnebin (2006, p. 30), está inscrito "[...] na própria relação do homem com a natureza, consigo mesmo e com seus companheiros; uma relação inscrita no desenvolvimento da techné (da técnica, do trabalho) e do logos (da linguagem e da razão)". Entretanto, o fato de Prometeu estar de posse do esclarecimento não lhe tira o peso da condição trágica. 
Forçado pela dominação, o trabalho humano mediado pela ciência e pela técnica tendeu sempre a se afastar do mito, voltando a cair sobre esse influxo, levado pela mesma dominação (ADORNO; HORKHEIMER, 1985). O fato de a ciência retirar o homem das mãos dos deuses não lhe poupa de continuar preso à sua própria natureza.

Trazendo o mito para uma interpretação contemporânea das ciências/tecnologias, essas potencializam/ampliam nossa condição corporal para além de sua natureza, seja no âmbito da saúde, da performance ou da beleza. A ciência cria tecnologias que produzem bens de consumo no mercado da beleza; feitas para alcançar o corpo "mitificado" pelo belo. Todas estas mercadorias estão expostas nas prateleiras do mercado do corpo. No entanto, não basta somente que o logos crie técnicas que potencializem o belo no corpo, é preciso que haja o convencimento, é preciso que haja o mito. Ou seja, é preciso que a ideia de "fazer uma lipoaspiração ou pôr silicone" sejam sustentadas por um mito que as signifiquem como bela.

Libertar o homem da influência mítica sempre foi o objetivo da filosofia - o esclarecimento - e assim, historicamente, o logos foi respondendo a cada demanda histórica da humanidade. A todos os esclarecimentos dados sucumbiam, assim, os mitos. No entanto, o mercado neoliberal se apropria do logos para criar seus mitos.

Com a difusão da economia mercantil burguesa, o horizonte sombrio do mito é aclarado pelo sol da razão calculadora, sob cujos raios gelados amadurece a sementeira da nova barbárie. Forçado pela dominação, o trabalho humano tendeu sempre a se afastar do mito, voltando a cair sob o seu influxo, levado pela mesma dominação (ADORNO; HORKHEIMER, 1985, p. 38).

Sendo assim, é preciso que sejam também criadas as "técnicas de si", aquelas que fazem com que os indivíduos criem para si uma necessidade de comportamento na busca e apropriação do corpo belo; é necessário criar uma cultura do belo; projetar signos, imagens. 
Trata-se da formação de um sujeito que se autocontrola, autovigia e autogoverna a partir desse mito que cumpre a função de seu alter ego.

Em nosso entender, a necessidade de a filosofia - assim como a ciência - recorrer a alguns recursos do mito demonstra que o pensamento racional não possui apenas como tendência o tratamento da verdade de modo direto. Platão, assim como os filósofos modernos, precisava convencer; necessitava da eloquência do mythos, justamente para que seu discurso se efetivasse como prática política e social no interior da polis. A tentativa filosófica, portanto, de situar o logos, cuja exposição dos resultados da investigação não poderia recorrer e apelar senão para a inteligência crítica do leitor e do ouvinte, parece fracassada, na medida em que, por uma condição comunicativa de todo discurso, seja ele lógico ou mito-lógico, que necessita da participação emocional e estética, sympatheia (VERNANT, 2006).

A questão da sympatheia também implica certa necessidade do filósofo em convencer seu interlocutor, não sendo a demonstração da verdade atitude suficiente para gerar implicações políticas no interior da polis. Não obstante, é por essa via que compreendemos Adorno e Horkheimer (1985) quando argumentam que o esclarecimento da razão também implica dominação e exploração no sentido da governabilidade dos homens por meio de seu apequenamento. Tal entendimento provém de suas leituras da filosofia de Nietzsche, que em o "Nascimento da Tragédia" já acusava a duplicidade contraditória do esclarecimento entre a soberania do espírito e sua potência hostil, próprio de Ulisses em sua Odisseia homérica.

De tal modo, o logos do mythos e o mythos do logos agem dialeticamente em uma tensão tal que eleva a inteligência e a emoção humanas à possibilidade de esclarecer e enganar, de libertar e aprisionar, de trazer a vida e de matar, de fazer acordos de paz e de guerra, de transformar o belo em feio e o feio em belo. A função estética do mythos em parceria com o logos funda a prática da 
propaganda (ADORNO; HORKHEIMER, 1985) como um modo de eloquência para convencer por meio da razão, responsável por mostrar uma verdade, de tal modo que essa última não é suficiente para gerar alguma transformação nos homens, pois esses necessitam serem convencidos da verdade. Do contrário, não haveria consciência capaz negar algo expresso como verdade. Assim vemos a necessidade de religiosos, de políticos e de comerciantes convencerem os povos de suas verdades por meio do efeito estético da propaganda amparada na narrativa mítica, ou seja, no mytholegein. Paradoxalmente, o esclarecimento também mitifica os povos (ADORNO; HORKHEIMER, 1985).

Cria-se uma lógica mítica na qual o corpo é dominado, seduzido e mobilizado pela busca de padrões de beleza. O sujeito é fantasmagorizado por um ideal de corpo, que lhe projeta um desejo - um alter ego. O trabalho é de cunho "hipnótico", no qual o sujeito sonâmbulo projeta seus sonhos. É atuando na gestão do desejo e esquemas de percepção que a mítica da beleza sugere cuidados e gestos específicos, é desta forma que ela afirma sua autoridade. A sedução e o efêmero do mito da beleza passam a organizar a vida dos sujeitos. Feito isso, a engrenagem do mercado do belo está garantida, pois o desejo impõe ao sujeito o consumo. Neste sentido, Lipovetsky (2009, p. 222) menciona que:

As necessidades são dirigidas e manobradas, a autonomia do consumidor se eclipsa em beneficio de um condicionamento da demanda orquestrada pelos aparelhos tecnoestruturais. O desígnio racionalizador e planificador do poder burocrático dá um salto para frente: depois da produção é a própria demanda que se encontra globalmente planificada, a publicidade produz necessidades estritamente adaptadas à oferta, permite programar o mercado, apanhar na armadilha a liberdade dos consumidores, a sociedade em seu conjunto tende a tornar-se um sistema circular, sem exterioridade, sem diferença, sem acaso.

É nesta sociedade que os indivíduos vivem a ostentação pela beleza corporal que, por seu misticismo, nos remete à dinâmica da 
fruição, do sonho, do superficial, do efêmero; que por seus sortilégios nos remete ao mito de Morfeu. Morfeu era o maior de todos os Onirus (deus dos sonhos), tinha a habilidade de assumir qualquer forma humana e aparecer nos sonhos. A droga morfina tem seu nome derivado de Morfeu, visto que ela propicia ao usuário sonolência e efeitos análogos aos sonhos. É dessa forma que muitos sujeitos são tomados pelos padrões de beleza corporal, eles se apropriam de um sonho de corpo que passa a assumir o papel de alter ego. $\mathrm{O}$ sujeito subordina seu corpo às suas vontades e cria nele um duplo: "o eu que é" e "o eu projetado no seu sonho". No entendimento de Le Breton (2011, p. 248):

Quanto mais o sujeito se centra nele mesmo, mais seu corpo assume importância ao ponto de invadir o campo de suas preocupações e de situá-las em uma posição dual. A obstinação do sujeito em relação ao seu próprio enraizamento corporal, a ex-tase do corpo toca então seu ponto de incandescência. $\mathrm{O}$ corpo torna-se um duplo, um clone perfeito, um alter ego.

A analogia onírica a qual nos remete Morfeu também dialoga com a ciência na medida em que muito do que chamamos hoje de realidade foi ficção um dia - foi um sonho da ciência. A ciência sonha e a partir do sonho cria a tecnologia para materializá-la em forma de produto. Os produtos tecnológicos criados pela ciência são a materialização das personificações oníricas que saem do plano imaginário e passam a circular no âmbito do real. "De fato, a produção nunca é simples, a produção técnica é, por definição, complexa, porque se dá no interior de um esquema ou plano marcado por uma pretensão ou por um caráter sistemático" (BÁRTOLO, 2007, p. 214).

Para auxiliar as pessoas nessa busca frenética pelo corpo belo, o mercado oferece um amplo repertório de produtos, práticas corporais e intervenções cirúrgicas que prometem adequá-los aos padrões, deixando seus corpos belos e prontos para serem exibidos. A cirurgia de reparação plástica, a aplicação de próteses de silicone e a lipoaspiração são os produtos que vêm crescendo em termos de demanda. $\mathrm{O}$ corpo, assim, deita-se na mesa cirúrgica, leia-se aqui 
metaforicamente "leito de Procusto4", a fim de "ficar dentro da medida". Para Soares (2008, p.76):

A medida inaugura um modelo de olhar e ao mesmo tempo um modo de intervir, materializando com intensidade, e quase mecanicamente, os processos de conformação dos corpos [...]. Medir torna-se, de fato, a ação e a intenção primeira para domesticar o corpo e enquadrá-lo em supostas normalidades. Medir o peso, a força, a resistência, a velocidade, a flexibilidade, e hoje mais intensivamente, medir os índices de massa corporal [...].

Assim, dois sonhos se materializam na mesa de cirurgia: o da pessoa que foi sanar as necessidades do seu duplo imaginário - alter ego; e o sonho da ciência, que se materializa sob o fio do bisturi e da cânula de sucção do aparelho lipoaspirador. As biotecnologias - fruto do logos - com seus instrumentos e próteses adequam o corpo a um determinado padrão de beleza - o logos permite a encarnação do mito pela técnica. Quando o tema é mitologia e beleza, o mito de Narciso $^{5}$ assume centralidade para conjecturarmos algumas questões. O mito de Narciso é iconográfico quando se tem como foco a idolatria pela imagem corporal, a exagerada paixão pelo próprio corpo, o excessivo trabalho de autoadoração da beleza física. Ele é central quando se fala de pessoas que amam mais a si próprias (seu corpo) do que as outras - enamorados de si. Lipovetsky (2009, p. 159) deixa clara esta relação tensiva entre Procusto e Narciso ao discorrer sobre o corpo:

\footnotetext{
${ }^{4}$ Procusto era um famoso salteador de uma antiga região grega. Sanguinário ao extremo, Procusto não se limitava a assaltar os viajantes que transitavam pelas estradas onde ele exercia sua atividade criminosa, mas também os submetia a um suplício bárbaro: os prisioneiros eram colocados em uma cama, e os de pequena estatura, que não ocupavam toda a extensão do leito, sofriam um processo de estiramento com cordas ligadas a roldanas, para que se adaptassem perfeitamente a ele; já os de tamanho maior, tinham simplesmente as partes que sobravam cortadas a machado.

${ }^{5}$ De forma sintética, conta o mito que certo dia Narciso parou em um lago cristalino para beber água e ali viu sua imagem refletida sobre o lago e por ela se apaixonou. Narciso ficava dias inteiros admirando seu reflexo na água. Um dia, de tão apaixonado, Narciso mergulhou na ânsia de pegar-se e foi sempre mais fundo no lago, até morrer afogado.
} 
Investe-se em todas as regiões do corpo; o narcisismo analítico detalha o rosto e o corpo em elementos distintos, cada um deles afetado por um valor mais ou menos positivo: nariz, olhos, lábios, pele, ombros, seios, quadris, nádegas, pernas são adjetivo de uma autoapreciação, de uma autovigilância que acarretam "práticas de si" específicas, destinadas a valorizar e a corrigir tal ou tal parte do físico.

No entanto, a busca desenfreada pela apropriação mítica dos signos de beleza pode deixar sequelas. Alguns indivíduos acabam por incorporar em suas vidas uma busca compulsiva pelo corpo perfeito de maneira exagerada, e esses excessos podem acarretar alguns distúrbios de comportamento, como é o caso da anorexia, bulimia, ortorexia, entre outras. $\mathrm{O}$ mito do belo suspende a aparência a um primeiro plano, de tal maneira que alguns sujeitos pagam com a própria vida o preço pela conquista da mesma. A anoréxica está envenenada de padrões que ela consome para ser bela, ela traz tatuada na carne a intoxicação de um corpo que se alimenta de sua própria fome de ser belo e definha como que por um processo de autofagia.

Esse torpor doentio pelo belo pode novamente estar ancorado em Narciso. Do ponto de vista etimológico, Brandão (1987) menciona que a palavra Nárkissos tem o elemento nárke, que, em grego, significa "entorpecimento", e que á a base etimológica da palavra "narcótico" e de toda uma vasta família com o elemento narc.

Será que há alguma forma de transcender a condição de viver de forma mitológica as questões ligadas ao corpo na apropriação do belo na modernidade? O princípio fundante do logos seria mesmo fazer o homem superar a condição mitológica na qual está inserido/ aprisionado, para então com suas próprias mãos e razão fundar uma nova história e, por consequência, um novo destino; rompendo com a condição alienante do mito do consumo do belo? Será que estamos fadados a uma condição mitológica ou outra operada pelo logos enquanto condição da linguagem humana? 


\section{ConSIDERAÇÕES FINAIS}

Embora distante cronologicamente, Odisseu e outros mitos gregos - equivocadamente interpretados como primitivos - devem nos servir como espelho da nossa condição mito-lógica em face aos paradigmas da beleza corporal na modernidade. O homem deve ser visto como mythologein, ou seja, como mistura de contrários, e, portanto, nessa dialética, enquanto contradição - como sendo a própria contradição e não o elemento da superação sintética de sua condição alienada e religiosa por meio da razão esclarecida ou pensamento filosófico.

Retomando a hipótese inicial do trabalho, podemos observar que embora a busca contemporânea pela beleza ocorra pelos caminhos - métodos - racionalistas e instrumentais da ciência com base em seu desenvolvimento biotécnico e biotecnológico, a adesão humana ao movimento político, social, cultural e econômico em direção aos modelos de beleza ocorre por meio de narrativas míticas capazes de articular efetivamente os benefícios da razão instrumental e o sonho da perfeição. Mais do que isso, a ciência contemporânea parece estar a serviço da materialização das ficções e fixações mitológicas da beleza ideal e universal herdadas do Ocidente grecoromano contra todo e qualquer relativismo estético. Nesse sentido, ciência e mito na modernidade estabelecem uma luta contra o caráter trágico do mito grego no sentido dos artifícios do logos científico enquanto caminho do possível. Contudo, essa sinergia moderna entre mito e logos ainda parece esbarrar nos signos do trágico: a velha ontologia que nos leva do nascimento à morte passando pelos dramas edípicos da infância e da velhice.

Com efeito, ao dialogarmos no texto com os mitos de Odisseu e Narciso em face ao homem moderno alienado ao mito do corpo belo, também implica acusar a necessidade de denunciarmos os limites do esclarecimento na medida em que ele serve para a proposição de outros mitos. Nem Sócrates, nem Platão, nem o 
Iluminismo, não se libertaram dos domínios do mythologein; tampouco nossa filosofia moderna pautada na relação do mythos e do logos do belo. Ou seja, a condição mito-lógica do homem é insuperável. 
From the governability of the Mythos to the enlightenment of the Logos: Narcissus, Odysseus and the body beauty patterns

Abstract: This work is the synthesis of a bigger philosophical research that presents the epistemological foundations of mythos and logos and its relations with the western experience. The text intents the conflicts and contradictions of the mythos and logos relation related to the problems of the governability and enlightenment of the individuals, anchoring the behaviors and body beauty patterns of the modernity. So, we suspended the Odysseus and Narcissus myth to, facing the modern man alienated to the body beauty myth, defend the thesis of the insuperable myth-o-logic condition of the man.

Keywords: Mythos/Logos. Body beauty patterns. Governability. Enlightenment.

De la gobernabilidad del Mythos al esclarecimiento del Logos: Narciso, Odiseo y los cánones de belleza corporal

Resumen: El trabajo es la síntesis de una investigación filosófica más amplia que presenta los fundamentos epistemológicos del mythos y logos y sus relaciones con la experiencia occidental. El trabajo tensiona los conflictos y contradicciones de la relación mythos y logos en lo que se refiere a los problemas de la gobernabilidad y el esclarecimiento de los individuos teniendo como fundamento los comportamientos y los cánones de belleza corporal en la Modernidad. Con ese objetivo cuestionamos los mitos de Odiseo y Narciso mirando al hombre moderno alienado al mito del cuerpo $Y$ defender la tesis de que la condición mito-lógica del hombre es insuperable.

Palabras-clave: Mythos/Logos. Modelos de belleza corporal. Gobernabilidad. Esclarecimiento. 


\section{REFERÊNCIAS}

ADORNO, T. W. HORKHEIMER, M. Dialética do esclarecimento: fragmentos mitológicos. Tradução de Guido Antônio de Almeida. Rio de Janeiro: Zahar, 1985.

BÁRTOLO, J. Corpo e sentido: estudos semióticos. Covilhã, Portugal: LabCom, 2007.

BRANDÃO, J. S. Mitologia grega. Petrópolis/RJ: Vozes, 1987. v. 2.

BULFINCH, T. O livro de ouro da mitologia grega: história de deuses e heróis. Tradução David Jardim Júnior. 26. ed. Rio de Janeiro: Ediouro, 2002.

GAGNEBIN, J. M. Lembrar escrever esquecer. São Paulo: Editora 34, 2006.

JAPIASSÚ, H.; MARCONDES, D. Dicionário básico de filosofia. 3. ed. rev. e ampl. Rio de Janeiro: Zahar, 2001.

JESI, F. O mito. Tradução de Lemos Azevedo. Lisboa: Editorial Presença, 1988.

LE BRETON, D. Antropologia do corpo e modernidade. Tradução de Fábio dos Santos Creder Lopes. Petrópolis, RJ: Vozes, 2011.

LIPOVETSKY, G. O império do efêmero: a moda e seu destino nas sociedades modernas. Tradução de Maria Lucia Machado. São Paulo: Companhia das Letras, 2009.

MELO-FILHO, D. Repensando os desafios de Ulisses e Fausto: a saúde, o indivíduo e a história. Caderno de Saúde Pública, Rio de Janeiro, v. 11, n. 1, p.5-20, jan./ mar. 1995.

NIETZSCHE, F. O nascimento da tragédia. Tradução de Antonio Carlos Braga. São Paulo: Escala, 2007.

PLATÃO. A República. Tradução de Leonel Vallandro. 23. ed. Rio de Janeiro: Ediouro, 1996.

RINALDI, M; LARA, L. M; RINALDI, I. P. B. Analogias da atividade física e saúde com o mito de Ulisses e as sereias. Revista da Educação Física da UEM, Maringá, v. 19, n. 3, p. 391-401, 2008.

SILVA, P. N. G.; GOMES, E. S. L. Eternamente jovem: corpo malhado, ficção televisual e imaginário. Revista Pensar a Prática, Goiânia, v. 11, n. 2, p. 197-209, 2008.

SOARES, C. L. Pedagogias do corpo: higiene, ginástica, esporte. In: RAGO, M.; VEIGA-NETO, A. Figuras de Foucault. 2. ed. Belo Horizonte: Autêntica, 2008. p.75-86. 


\section{Artigos Originais}

VERNANT, J-P. Mito e sociedade na Grécia antiga. Tradução de Miriam Campello. 3. ed. Rio de Janeiro: José Olimpio, 2006.

VERNANT, J-P. Mito e pensamento entre os gregos. Tradução de Haiganuch Sarian, 2. ed. Rio de Janeiro: Paz e Terra, 1990.

Endereço para corespondência:

Renato Izidoro da Silva

Rua Jordão de Oliveira n. 96 casa 11

Bairro Atalaia

Aracaju/SE

CEP: $49037-330$

\section{Fabio Zoboli}

Rua Rosalina n. 80 aptm. 302

Condomínio Luzes do Farol - Bloco Pacífico

Bairro: Farolândia

Aracaju/SE

CEP: 49032-150

Recebido em: 03.04.2013

Aprovado em: 30.07 .2013 